\section{Was hilft bei obstruktiver Schlafapnoe?}

\author{
Eine obstruktive Schlafapnoe steht mit Risikofaktoren für \\ eine Atherosklerose in Beziehung, wie z.B. Bluthochdruck, \\ Insulinresistenz und subklinischer Inflammation. Zudem \\ sind die Betroffenen meist stark übergewichtig, was ebenfalls \\ das kardiovaskuläre Risiko erhöht. Wie dieser subklinische \\ proinflammatorische Zustand vermindert werden kann, hat \\ ein Team aus den USA untersucht. \\ N Engl J Med 2014; 370: 2265-2275
}

In einer prospektiven, randomisierten Studie sind Julio Chirinos und seine Kollegen der Frage nachgegangen, welche Maßnahme am stärksten dazu beiträgt, die Konzentration des C-reaktiven Proteins (CRP) bei Patienten mit obstruktiver Schlafapnoe zu senken. Zu diesem Zweck verglichen sie den Effekt einer CPAP-Therapie (Continuous Positive Airway Pressure) mit den Auswirkungen eines Gewichtsverlustes sowie einer Kombination der beiden Maßnahmen. Einschlusskriterien waren ein deutliches Übergewicht (Body Mass Index $\geq 30 \mathrm{~kg} / \mathrm{m}^{2}$ ), eine polysomnografisch gesicherte mäßig bis schwer ausgeprägte obstruktive Schlafapnoe (ApnoeHypopnoe-Index $\geq 15$ ) und eine CRP-Ausgangskonzentration von mehr als $1 \mathrm{mg} / \mathrm{l}$. Die Studienteilnehmer wurden nach dem Zufallsprinzip einer von 3 Gruppen zugewiesen: Die Teilnehmer der ersten Gruppe

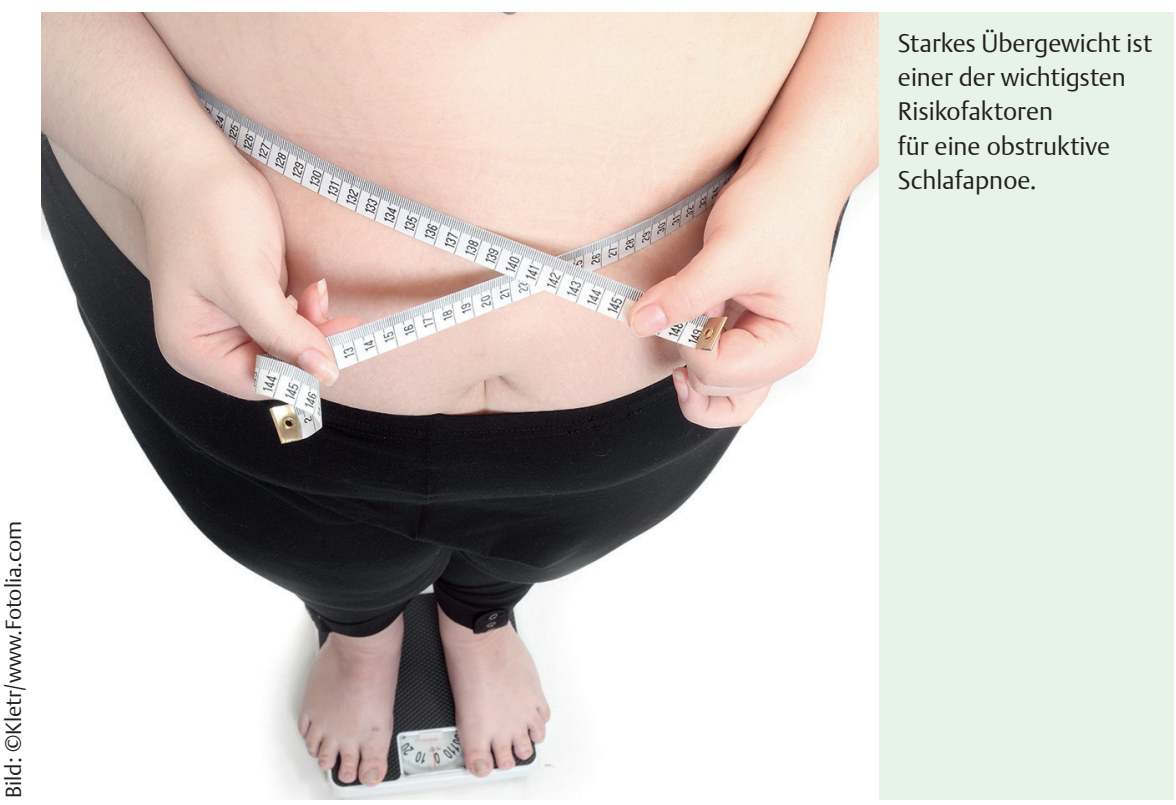

bzw. 7,0 kg abgenommen (nur Diät bzw. Diät plus (PAP). Die CPAP-Maske war in beiden Gruppen (CPAP alleine oder in Kombination) durchschnittlich 4 Stunden pro Nacht getragen worden. An die Therapievorgaben hatten sich insgesamt $90 \mathrm{~Pa}-$ tienten gehalten, 39 in der CPAP-Gruppe (Maskenatmung mind. 4 Stunden pro Nacht in 70\% der Nächte), 27 in der Gewichtsverlust-Gruppe (Gewichtsverlust mind. 5\% des Ausgangswerts) und 24 in der Kombinationsgruppe.

\section{Positive Effekte bei Gewichtsverlust \\ $\nabla$}

In der Gruppe mit Gewichtsverlust und in der Kombinations-Gruppe fand sich eine gegenüber dem Ausgangswert deutlich verminderte CRP-Konzentration ( $p$ jeweils <0,001); in der CPAP-Gruppe war dies nicht der Fall. Beim Vergleich der beiden Monotherapien schnitten die Patienten mit Gewichtsverlust besser ab als die CPAP-Patienten. Ebenso besserten sich die Insulinsensitivität und die Serumtriglyceridkonzentrationen nach Gewichtsverlust, wobei die zusätzliche CPAP-Atmung insgesamt keine weitere Verbesserung erbrachte.

Ähnlich verhielt es sich mit den Blutdruckwerten: Der systolische Druck hatte sich in allen 3 Gruppen nach 24 Wochen verringert, insgesamt ohne Unterschied zwischen den Gruppen. Wertete man aber nur die Daten von Teilnehmern aus, die sich an die Vorgaben gehalten hatten, zeigte die Kombinationsmaßnahme eine ausgeprägtere Blutdrucksenkung als eine der beiden alleinigen Interventionen (-14,1 vs. $-6,8 \mathrm{mmHg}$ bei Gewichtsabnahme und $-3,0 \mathrm{mmHg}$ bei CPAP-Atmung).

Fazit
Bei obstruktiver Schlafapnoe sind Maß-
nahmen zur Verminderung des Körper-
gewichts die effektivste Methode, um
die CRP-Konzentration - als Surrogat-
parameter für das Herz-Kreislauf-Risi-
ko - zu senken, so die Autoren. Eine
CPAP-Atmung könnte zusätzliche Vor-
teile bringen, wenn die Teilnehmer die
Maske wie vorgegeben tragen.

Dr. Elke Ruchalla, Trossingen 